\title{
Curriculum Development in Higher Education: A Case Study from University of Venda
}

\author{
Jabulani R Gumbo
}

\begin{abstract}
Curriculum development in the higher education sector, such as in the University of Venda is reviewed. The role played by various stakeholders in the shaping of Bachelor Earth Sciences in Hydrology and Water Resources curriculum development in higher education is also discussed. Curriculum development consist of knowledge which is factual and knowledge generation through research; it examines reality in daily life; looks at values that underlie the teaching and learning $(\mathrm{T} / \mathrm{L})$ and what and whose interests are being served by a T/L curriculum. There are international and national contextual factors that have a bearing on the development of the curriculum. The SAQA reforms on the HE curriculum in South Africa have contributed to the review of our curriculum and led to the production of an epistemically diverse curriculum. The current curriculum for the Bachelor of Earth Sciences in Hydrology and Water Resources has a minimum credit value of 480 (in our curriculum the credit value is 640) and the post-graduate degree of the Bachelor of Earth Sciences Honours in Hydrology and Water Resources has a minimum credit value of 180 (our curriculum the credit value is 240). In addition, an epistemically diverse curriculum is important as it empowers the students with generic skills (both transferable and transferring skills) and facilitates their lifelong learning.
\end{abstract}

Keywords-About four key words or phrases in alphabetical order, separated by commas.

\section{INTRODUCTION}

The word curriculum is defined differently by academics. Myself I define curriculum to mean a syllabus of teaching and learning. Other institutions dealing with higher education such as Council on Higher Education, University of Venda and Rhodes University may define curriculum differently. The Council on Higher Education [1:5] defines the curriculum as "the planned learning experience that students are exposed to with a view to achieving desired outcomes in terms of knowledge, competencies and attributes". Thus, from this definition, the emphasis on planned learning shows that the curriculum is dynamic document that must a follow structured set of learning objectives. The University of Venda [2] has defined the curriculum as "the intended learning outcomes, content and subject matter, activities and experiences, and assessment and evaluation, the purpose of which is to enable

Manuscript received October 19, 2020. The author was provided with a scholarship to undertake post graduate diploma in Higher Education at Rhodes University by the University of Venda, Teaching and Development Grant 0791.

Prof Jabulani Ray Gumbo is with the Department of Hydrology \& Water Resources, University of Venda the achievement of learning goals". The University of Venda definition even goes a deeper by mentioning content and subject matter to indicate that curriculum has these attributes.

According to Hussey and Smith [3:360] define articulated curriculum as 'one in which all the elements both influence and interact with each other in order to stimulate and support active learning and... reflects what happens in classrooms: a mass of intentions, ambiguities and interactions'. Whereas the definition of Hussey and Smith [3] speaks about interactive elements all working cumulatively to enhance and support student learning. The Rhodes University (RU) [4:4] defines ' 'curriculum' is generally used to refer to the syllabus - the list of subjects, topics and the text included in a course of study. It is more than that. It incorporates subject content and skills, the manner of teaching and assessment that is followed, the philosophical outlook of the teacher and who the learners are." The RU definition includes the component of teacher and learner recognising the central role played by both the teacher and student.

The types of curriculum that are available are: hidden curriculum; curriculum in action; curriculum on paper; planned curriculum; received curriculum; formal and informal curriculum. But I will dwell on the hidden curriculum since, since I am also part of promoting this 'hidden curriculum'.

Lempp and Seale [5] discussed the hidden curriculum at medical institution in the United Kingdom for the training of medical students. The hidden curriculum is defined as a: "the set of influences that function at the level of organizational structure and culture including, for example, implicit rules to survive the institution such as customs, rituals, and taken for granted aspects" '[5:770]. Thus, this is addition to the official curriculum that the medical students are exposed. During the same study by Lempp and Seale [5] showed that this hidden curriculum encourage competitive behaviour rather than cooperation among the medical students and attention with the superiors or medical consultant in order to get ahead of others

However, when I review this it implies that the hidden curriculum though 'no stated learning outcomes' or 'no written learning outcomes' it must be followed by medical students in order to successfully complete their studies. This bring one aspect that during my teaching and learning, I always advise my Hydrology students to register and learn to drive a motor car and then acquire a driver's license whilst at the University. The student then has acquired a competitive advantage in that prospective employers such as the Department of Water Affairs (DWA) are always recruiting hydrology students 'with a driver's license [6]. The main reason is that the employer DWA 
cannot recruit a driver for new staff member who has the Hydrology qualification! Secondly during my lectures, I always to encourage my Hydrology students to register with professional bodies as Water Institute for Southern Africa (WISA) and South African Council for Natural Scientific Professions.

\section{CONTEXTUAL FACTORS THAT IMPACT ON CURRICULUM DEVELOPMENT}

Curriculum development consist of knowledge which is factual and knowledge generation through research; it examines reality in daily life; looks at values that underlie the teaching and learning $(\mathrm{T} / \mathrm{L})$ and what and whose interests are being served by a T/L curriculum. The sources of the impact of curriculum are varied and may be influenced by national and international trends.

\section{A. International level}

The contacts that are made for national and international universities may be used for benchmarking of the curriculum. This is important as it is necessary to 'see' what other national universities are doing with similar curriculum. The international universities are also important as they allow for cross pollination of ideas and thoughts over a similar curriculum. Finally, regarding the University of Venda, the contacts at international and national universities are used in reviewing the Bachelor of Earth Science Hydrology and Water Resources curriculum.

\section{B. National level}

\section{1) National Qualifications Framework}

The National Qualifications Framework (NQF) has, as per Higher Education Qualifications Sub-Frameworks (HEQSF), 10 exit levels. The Bachelor of Earth Sciences in Hydrology and Water Resources is a four-year professional degree program with an exit level of NQF 8 (professional degree) and the Bachelor of Earth Sciences Honours in Hydrology and Water Resources consist of an added one year of study (Figure 1). Both programs articulate into the Master level. A student with a water related Bachelor degree can study for the Bachelor of Earth Sciences Honours in Hydrology and Water Resources. The Higher Education Qualifications Sub-Framework (HEQSF) [7] is part of SAQA and its aims are to determine the qualification types and characteristics as well as purposes of all higher education qualifications in South Africa.

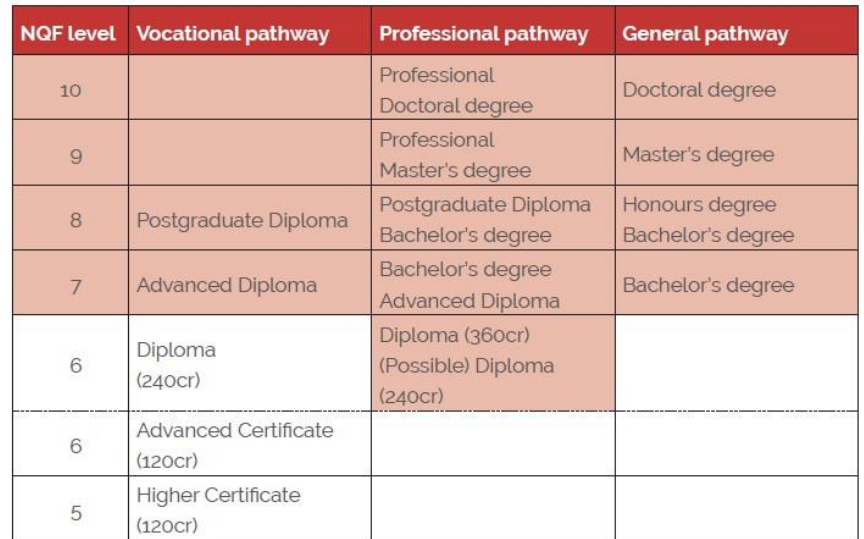

Fig. 1: National Qualifications Framework showing exit levels [8:26]

The exit levels for Bachelor of Earth Sciences in Hydrology and Water Resources is NQF level 8 and the student must have completed with a total of 480 credits. The Bachelor of Earth Sciences Honours in Hydrology and Water Resources has a credit value of 120 . The HEQSF state that the credits are accumulated by the student during the four year of study and these involve attending lectures, writing assignments, laboratory practicals, field trips, work integrated learning, tests and examinations and self-study. The value of each credit is 10 notional study hours.

\section{2) Professional bodies}

The curriculum of the undergraduate modular program, Bachelor of Earth Sciences in Hydrology and Water Resources and the post-graduate degree of Bachelor of Earth Sciences Honours in Hydrology and Water Resources should be accredited with professional bodies. These bodies include the South African Council for Natural Scientific Professions (SACNASP) in terms of the Natural Scientific Professions Act (Act 27 of 2003) and the Engineering Council of South Africa (ESCA).

The mandate of the South African Council for Natural Scientific Professions is to protect the public interest in relation to the work of registered Professional Natural Scientists, e.g. safeguard public health and safety from adverse consequences of natural science activity' [9-10]. For a person to attain a Professional Natural Scientist status, they must show competences arising from an accumulation of academic study, training and experience. Hence, from the onset of the academic studies, SACNASP must be able influence the curriculum design and development and monitor the training of students through a periodic audit of the academic program. Thus, the South African Council for Natural Scientific Professions visited the University of Venda's Department of Hydrology and Water Resources in 2013 and evaluated the curriculum and other important aspects of the degree program. In addition, a student that would have completed and attained the Bachelor of Earth Sciences in Hydrology and Water Resources or Bachelor of Earth Sciences Honours in Hydrology and Water Resources is expected to register as a Candidate Natural Scientist after identifying a suitable mentor. I have been involved in mentoring some students and have assisted some to attain Professional Natural Scientist status. This mentoring is outside 
of the official curriculum and this is probably one areas of the hidden curriculum that I am involved in.

The DHET, SAQA and CHE also encourage professional bodies such as the South African Council for Natural Scientific Professions to be involved in the curriculum design and development at various IHEs. SAQA [11:4] formulated a policy and criteria with some of the following objectives:

Promote public understanding of, and trust in, professions through the establishment of a nationally regulated system for the recognition of professional bodies and for the registration of professional designations... Promote the protection of the public by professional bodies from malpractice related to the fulfilment of the professional duties and responsibilities of professionals registered with them.'

These objectives are like the objective set by the South African Council for Natural Scientific Professions meant to 'protect the public' and 'promote competency among the professionals'. In 2012, the DHET [12:5] through the Minister also directed SAQA,

'After consulting the Quality Councils [QCs] and recognized professional bodies concerned to advise me on how the relationship between professional designations and sub-frameworks should be clarified

The CHE [13:15] also stated that:

alignment between the award of a qualification by an institution and the extent to which it meets a professional body's requirements for designation is a matter that needs to be resolved between the awarding institution (or the sector as a whole) and the relevant professional body.

Thus, the DHET, SAQA and CHE seem to encourage the involvement of professional bodies in the curriculum design and development, however, the extent of this involvement is left to the awarding University institution and the professional body.

Our current curriculum for undergraduate modular program, Bachelor of Earth Sciences in Hydrology and Water Resources and the post-graduate degree, Bachelor of Earth Sciences Honours in Hydrology and Water Resources, have been submitted to South African Council for Natural Scientific Professions for review. In June 2012, South African Council for Natural Scientific Professions came to our University to interact with the stakeholders, members of staff and students as part of the engagement with the professional body and in order to enhance the curriculum. The visit sought to ensure that the curriculum is in line with the objectives of the professional body and the interests of employers.

\section{3) Employers}

Graduate students who would have obtained their four-year degree qualification can proceed to a Masters" study, create their own consulting companies or seek formal employment. Some of the organisations that have provided employment to these graduates include the Department of Water Affairs, Local and District Municipalities and some Professional Consulting companies. The Department of Water Affairs has in the past been the largest recruiter of our students and part of the recruitment criteria is a driver's license and registration as a Candidate or Professional Natural Scientist [6].

The employers do not influence the curriculum per se but they insist that the employee must register with a professional body such as the South African Council for Natural Scientific Professions [6]. Thus, the employer affect and influence the curriculum indirectly through their insistence that prospective employees register with a professional body. However, during our revision of the curriculum to bring it in line with SAQA requirements, outcomes, credits, etc., we consulted with the employers to obtain their views on the curriculum content.

\section{4) National universities and Science councils}

South African institutions such as the Universities of Zululand and Pretoria, offer a similar curriculum but differ in the NQF exit levels [14]. The University of Venda offers a Bachelor of Earth Sciences: Hydrology and Water Resources (SAQA Qualification ID: 17423, NQF Level 8), whereas the University of Zululand offers a Bachelor of Science: Hydrology (SAQA Qualification ID:62530, NQF level 7) and the University of Pretoria offers a Bachelor of Science: Earth Sciences (SAQA Qualification ID:6385, NQF level 7).

The science councils, which include the Council for Scientific \& Industrial Research (CSIR) and the Agricultural Research Council (ARC) are a valuable source of information in research (knowledge generation) and as sources of funding for contract research. The science councils are also a source of post graduate supervisors [15].

I have benefitted from the association with CSIR and ARC in the field of knowledge generation. I am a recipient of an over R350,000-00 CSIR grant for the studies of environmental risks arising from the disposal of nanowaste into the environment [16]. Nanowaste is wastewater that is generated when a nanoproducts, such as Nivea silver protect is applied to the body as a deodorant. The waste is a product of a bath or shower, where the nanoproduct is washed off the human body and this wastewater is coined nanowaste.

\section{5) Institutional level}

'The curriculum of the undergraduate and postgraduate modular programme addresses pressing national and community needs, in addition to the comprehension of the principles (and practice) of hydrology, hydrogeology, meteorology, fluid mechanics, and the quality and management of water as a resource' [17]. Thus, the curriculum should be aligned to the University of Venda's (Univen) vision, mission, institutional values and five-year strategic plan, 2012 to 2016 [18-19]. The curriculum should also comply with all Univen policies and regulations.

\section{Departmental level}

The design and review of the curriculum is initiated by the Head of Department (HOD) who gathers all the lecturers in the department and allocates the lecturers modules to review or redesign curriculum wise. The lecturers here are significant in the review as they are the experts in their fields and the originators as well as implementers of the curriculum. I was involved in the review of the following modules: first year level; HWR 1642 Water Quality Principles; second year level 
HWR 2541 Rural Water Supply and Sanitation, HWR2542 Data Information Systems and HWR2641 Water Law and Institutions; third year level HWR3643 Water Quality Management, and fourth year level HWR4543/5543 Water Supply Systems and HWR4643/5643 Water Treatment Processes. This review process includes consultation and benchmarking with: other South African Universities as well as with universities from the region and international landscape, employers such the Department of Water Affairs, Local and District Municipalities, and Professional Consulting companies and professional bodies such as the South African Council for Natural Scientific Professions (SACNASP) and the Engineering Council of South Africa (ESCA). Evidence of these consultation and bench marking exercises (external review) must be compiled and attached (feedback) to each module.

There was also consultation at a local level with the Centre for Higher Education and Teaching and Learning (CHETL) and the Institutional Planning and Quality Assurance (IPQA) who workshopped us on how, why, what and where the curriculum should be reviewed, improved, designed and developed. CHETL and IPQA ensured that the curriculum was aligned with the Univen vision, mission and institutional values, five-year strategic plan and the DHET, SAQA and CHE requirements. Once the curriculum was ready, the HOD submitted it the document to the Board of the School of Environmental Sciences for approval.

Thereafter, CHETL and IPQA facilitate the approval of the curriculum within the other Univen structures, such as the Academic Planning Committee (APC) and the Senate. Once the Senate has approved the curriculum it is then submitted to the University Council. It should be state that the different Univen structures also provide feedback on the curriculum which must be attended to before the reviewed curriculum document moves to the next level. When all the Univen structures are satisfied with the curriculum, IPQA then submitted the curriculum to SAQA for accreditation and CHE and DHET for registration. Again, these organisations, SAQA, DHET and CHE, may also propose changes to the curriculum which must be attended to before the curriculum is approved for offering to the students as a degree program. This process of curriculum design and review may take 2 to 3 years before the program is offered.

\section{Stakeholders}

In addition to the professional bodies, there are other stakeholders who must be consulted during the review or development of a curriculum. These stakeholders are former students (alumni); employers and scholarship funders; local communities and in the case of a rural university such as Univen, the traditional leadership.

\section{E. Students}

The current and former students (alumni) of the University of Venda are the consumers of the curriculum. Thus, it is imperative to consult and involve them in the review and development of the curriculum. The current students may contribute to the review and development through their active participation in the lecture evaluation exercises and by providing valuable student feedback through the completion of questionnaires. These student evaluations, if completed and collected over a period, can be a valuable source of information.

The alumni are a valuable source of information about the directions that the curriculum must take since they are already employed in private and public sector companies and universities. Thus, the alumni 'know' what criteria or 'critical outcomes' the employers are looking for from new employees. At the University of Venda, the Department of Communications and Marketing in June of 2012, established the Office of Convocation \& Alumni within the directorate with a view of encouraging the former students to form alumni chapters in various towns and cities of South Africa [19]. Some of the objectives of the Univen Alumni Association are: 'to help attract and assist prospective students to attend at Univen; to assist and support the University in increasing its academic standards'. These former students are the ambassadors of the University and are best placed to assist in the review and development of the curriculum and hence 'increasing its academic standards'. The consultation with the former students becomes part of the benchmarking process where their input assist in the redesign and review of the content of the curriculum. The improvement in the curriculum may in turn encourage other prospective students to enroll at the University. The former students of the Department of Hydrology \& Water Resources have indeed been forthcoming with their inputs and contributions in improving the curriculum.

\section{F. Employers and scholarship funders}

Employers have also contributed to the improvement of the content of the curriculum. This came after we had written letters to them soliciting their views and opinions. The employers are the final 'sink' in which the graduates must demonstrate their competency, skills and knowledge, hence their views are essential.

Scholarship and other funding organization, such as the NRF, WRC, CSIR, DAAD, DFID, Mintek, the Energy \& Water Services Education \& Training Authority (EWSETA) and Council of Geoscience are consulted in the review and development of the curriculum. It is important to consult this sector since they would want to 'pour' money where the students are expected to graduate within the prescribed times. Some of the scholarship funders have national and international networks which can be used to our advantage, especially during the review and design of the curriculum. The funders may even suggest contacts that may provide valuable feedback on the curriculum improvements.

\section{G. Local communities and traditional leadership}

The University of Venda is situated in a rural area and is surrounded by a rich cultural heritage. The local communities and traditional leadership may also contribute to the review and development of curriculum. I am of the view that communities and traditional leadership may be contacted to give their views and opinions on the specific local issue that can be included in the content of the curriculum. Hence, some significant information may be obtained from such interactions with the communities in field of knowledge generation.

My interaction with a few traditional leaderships in the Vhembe District over the years has assisted in my knowledge generation. For example, the villagers from the Mutale 
Municipality complained to the Vhembe Disaster Management Forum after several their cattle died after eating a plant called Muhau. The Vhembe Disaster Management Forum in turn contacted the Dean of School of Environmental Sciences to investigate the distribution of the plant and suggest measures that can be taken to manage the Muhau plant and thus prevent further cattle deaths. I was then contacted by the Dean to carry out the investigations.

My research findings did confirm that the Muhau plant is part of the Vangueria family. The Vangueria family of plants has been implicated in the past deaths of livestock (ruminants) in north-west Transvaal (present day Limpopo) and has been named gousiekte [20]. In addition, I arranged a field trip with 26 Univen students and equipped them with Global Positioning Systems (GPS) units in October 2013. The purpose of the field trip was to map the distribution of the Muhau plant and to produce a map showing its geographic location. We were greatly assisted, during the field excursion, by the local leadership in identifying the Muhau plant. Later a map showing the distribution of Muhau plant was made using the GPS coordinates by one of my Masters' student. However, the map that was generated did not really represent all the Muhau plants in the area. Thus, the next phase of the study is to use Remote Sensing and Satellite imagery to cover a larger area. The students that were involved in the field exercise benefitted in that there were able to apply their theory of GPS to a local challenge and will also later use Remote Sensing and Satellite imagery to determine the actual distribution of the Muhau plant.

III. ANALYSIS OF BACHELOR OF EARTH SCIENCE HYDROLOGY \& WATER RESOURCES CURRICULUM

The current curriculum for the Bachelor of Earth Sciences in Hydrology and Water Resources has a minimum credit value of 480 (in our curriculum the credit value is 640) and the post-graduate degree of the Bachelor of Earth Sciences Honours in Hydrology and Water Resources has a minimum credit value of 180 (our curriculum the credit value is 240). There are 18 modules in the first year, 9 modules in second year of study, 8 modules in third year and 8 modules in fourth year. The curriculum consists of university wide modules, fundamental, electives and core modules in which a student must pass in order to progress to the next level. The study of Luckett's [21] showed that an Australian study had proposed an undergraduate curriculum with compulsory core set of generic skills and content subjects that are taught as electives. Luckett [21] outlines further that SAQA reforms stipulated three types of learning in the curriculum content, which are: fundamental, core and elective. Fundamental learning 'ensures that the learner achieves the competence required to attain the qualification as well as providing the foundation for further learning'. The core learning 'breadth and depth to the curriculum, is related to a particular profession, career or field of specialization'. The elective learning 'enriches the curriculum by meeting the learners' own interests or by providing the advance specialization to the qualification'.

I teach the following modules: first year level HWR 1642 Water Quality Principles; second year level HWR 2541 Rural Water Supply and Sanitation; HWR2542 Data Information Systems, HWR2641 Water Law and Institutions; third year level; HWR3643 Water Quality Management; and fourth year level HWR4543/5543 Water Supply Systems and HWR4643/5643 Water Treatment Processes.

\section{IMPACT OF DISCIPLINARY KNOWLEDGE ON CURRICULUM}

The cognitive style of the discipline, Hydrology and Water Resources, is hard/applied science. The curriculum must embrace teaching and learning of 'hard facts' and practical aspects that underpin the theoretical aspects. My role as a teacher is to foster an environment that is conducive for teaching and learning and to induct the students into the discipline's ways of knowledge. My responsibility is the transformation or re-contextualisation of disciplinary knowledge into the curriculum.

According to the Biglan [22] model on the taxonomy of academic disciplines, Hydrology and Water Resources is classified as a 'hard and applied' discipline that is concerned with the application of knowledge. Jones [23] has recently used Holland's classification of academic disciplines, using the Educational Opportunities Finder, and thus classifies Hydrology and Water Resources under Investigative. In addition, to the Holland's classification, the 'faculty create academic environments inclined to require, reinforce, and reward the distinctive patterns of abilities and interests of students in a manner consistent with Holland [23]. This impacts on the curriculum by infusion socialization skills and the investigative faculty as the Hydrology \& Water Resources is 'more successful at socializing their students to the goals and ideals of their academic disciplines' [23].

According to Jones [23], the faculty in Investigative environments is able to motivate and empower their students by placing 'greater emphasis on students' development of such Investigative competencies as analytical abilities, mathematical skills, and scientific abilities while at the same providing few rewards for students' acquisition of "enterprising" competencies such as leadership and managerial skills, and persuasive abilities'. I also place greater emphasis on students' analytical abilities and mathematical skills, during my teaching and learning sessions, since these attributes are important in the module Water Treatment Processes.

Nevertheless, the lack of enterprising competencies in the curriculum means that the students cannot move to higher managerial positions. I have noted this with our graduate students who then take additional courses or degree programs in managerial finance and then later get promoted. The lack of enterprising competencies may also impact negatively on those students who upon graduation set up their own consulting companies. However, I have also observed that some of the enterprising students actual set up these consulting companies whilst at University of Venda and after graduation. I have encouraged these students and availed myself for further consultation, should they require any assistance in their enterprise.

\section{AN EPISTEMICALLY DIVERSE CURRICULUM}

The SAQA reforms on the HE curriculum in South Africa have contributed to the review of our curriculum and led to the production of an epistemically diverse curriculum. According to Luckett [20] there are four ways of knowing and learning what forms the basis of the epistemically diverse curriculum. The four ways are 'traditional cognitive learning of 
propositional knowledge'; learning by doing for the application of disciplinary knowledge'; 'learning experientially' and 'developing epistemic cognition to be able to think reflexively and contextually about one' learning'.

Thus, an epistemically diverse curriculum is required to expose the students to Mode 1 and Mode 2 knowledge production, but these have their own limitations. The concept of problem base learning is one such aspect that might link the four quadrants [20] and integrate with Mode 1 and Mode 2. The students can develop their own epistemic knowledge by applying the theory to a real-life problem and providing solutions. The epistemically diverse curriculum is important in that it will empower the students with generic skills (both transferable and transferring skills) and facilitates their lifelong learning.

\section{CONCLUSION}

The curriculum development is important in shaping the student and must respond to a few contextual factors in order to effectively train the students in higher education sector. There are different types of curriculum and these are: hidden curriculum; curriculum in action; curriculum on paper; planned curriculum; received curriculum; and formal and informal curriculum. A cultural responsiveness to the curriculum, for example, must include discussions on culture and teaching and learning as well as ethics. Though ethics is not part of standalone activity the registration of our students by professional bodies inculcates a sense of professionalism. In addition, an epistemically diverse curriculum is important as it empowers the students with generic skills (both transferable and transferring skills) and facilitates their lifelong learning.

\section{ACKNOWLEDGMENT}

The author was provided with a scholarship to undertake post graduate diploma in Higher Education at Rhodes University by the University of Venda, Teaching and Development Grant 0791 .

\section{REFERENCES}

[1] Council on Higher Education (CHE). A proposal for undergraduate curriculum reform in South Africa: The case for a flexible curriculum structure. 2013

http://www.che.ac.za/sites/default/files/publications/Full_Report.pdf (date accessed 25/03/2014)

[2] University of Venda (Univen). Curriculum Development and Review Policy, 2013

[3] Hussey, T., \& Smith, P. The uses of learning outcomes. Teaching in higher education, 2003, 8(3), 357-368. https://doi.org/10.1080/13562510309399

[4] Rhodes University. Policy on Curriculum Development and Review. 1998.

http://www.ru.ac.za/media/rhodesuniversity/content/institutionalplannin g/documents/curriculumdevelopment.pdf (date accessed 05/08/14)

[5] Lempp, H., \& Seale, C. The hidden curriculum in undergraduate medical education: qualitative study of medical students' perceptions of teaching. BMJ, 2004, 329(7469), 770-773.

https://doi.org/10.1136/bmj.329.7469.770

[6] Department of Water Affairs (DWA).Vacancies. 2012. http://www.dwaf.gov.za/vacancies/Ads12166.pdf (date accessed $25 / 07 / 2014$ )

[7] As approved by the Minister of Higher Education and Training (Notice 1040 of 2012; Government Gazette No. 36003 of 14 December 2012) in terms of the National Qualifications Act, 2008 (Act No. 67 0f 2008) and as contemplated in the Higher Education Act, 1997 (Act No. 101 of 1997).
[8] Council on Higher Education (CHE). Framework for Qualification Standards in Higher Education, 2013.

https://nr-online-1.che.ac.za/html_documents/2.Framework\%20Qualific ation\%20Standards\%20Development_2015.pdf

[9] SACNASP. Requirements for registration. 2020.

https://www.sacnasp.org.za/requirements-for-registration (date accessed 19.10.2020)

[10] No. 27 of 2003: Natural Scientific Professions Act, 2003

[11] SAQA. Policy and Criteria for Recognising a Professional Body and Registering a Professional Designation for the Purposes of the National Qualifications Framework Act, Act 67 of 2008, 2008:4.

http://www.saqa.org.za/docs/guide/2012/policy_2008.pdf (date accessed $25 / 07 / 2014$

[12] DHET. Department of Higher Education and Training (DHET). Determination of the Sub-Frameworks that comprise the National Qualifications Framework. General Notice 1040 of 2012. (2012:5) http://www.saqa.org.za/docs/pol/2012/determination.pdf (date accessed 25/07/2014)

[13] Council on Higher Education (CHE). Standards Development in Higher Education, 2013:15

http://www.che.ac.za/sites/default/files/publications/second_draft_frame work_for_qualification_standards_in_higher_education_january_2013.p df (date accessed 25/03/2014)

[14] NCAP. Careers. 2014.

http://ncap.careerhelp.org.za/learningprovidersforqualification/generalqu alification/5ce8decf-bbe5-4f62-bf19-61731b6e4ef4/occupation/afa3a13d -a478-441d-ab1e-13ddc491f04d

(Date accessed 25/07/2014) https://doi.org/10.1016/B978-0-12-800631-3.50002-2

[15] Gumbo JR. Postgraduate Diploma in Higher Education. Unpublished Portfolio. Rhodes University, 2016.

[16] Mbedzi A, Gumbo JR. The release of silver and aluminium into wastewater from commercially available silver spray deodorant and soap B. Int'l Conf. on Advances in Science, Engineering, Technology \& Natural Resources (ICASETNR-16) Nov. 24-25, 2016 Parys (South Africa)

[17] University of Venda (Univen). Vision and Mission of the University of Venda, 2014

http://www.univen.ac.za/index.php(date accessed 26/03/2014)

[18] University of Venda (Univen). Univen strategic plan 2012-2016 http://www.univen.ac.za/docs/UnivenStratDoc2012New_Lowres.pdf(dat e accessed 25/07/2014)

[19] University of Venda (Univen). Nendila. 2012b:4 (date accessed 25/07/2014)

http://www.univen.ac.za/docs/nendila/NendilaAprilMay2012low.pdf (date accessed 25/07/2014)

[20] Verstraete, B., Van Elst, D., Steyn, H., Van Wyk, B., Lemaire, B., Smets, E., \& Dessein, S.). Endophytic bacteria in toxic South African plants: identification, phylogeny and possible involvement in gousiekte. PloS one, 2011,6(4), e19265 https://doi.org/10.1371/journal.pone.0019265

[21] Luckett, K.). A proposal for an epistemically diverse curriculum for South African higher education in the 21st century. South African Journal of Higher Education, 2001,15(2), p-49. https://doi.org/10.4314/sajhe.v15i2.25354

[22] Biglan, A. The characteristics of subject matter in different academic areas. Journal of Applied Psychology, 1973, 57(3), 195-203. https://doi.org/10.1037/h0034701

[23] Jones, W. A. Variation among academic disciplines: An update on analytical frameworks and research. Journal of the Professoriate, 2011, $6(1), 10$.

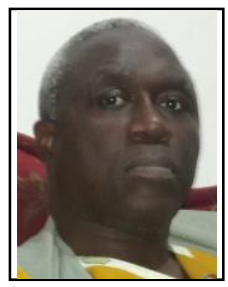

Prof Jabulani Ray Gumbo graduated with a $\mathrm{PhD}$ in Water Resources Management from University of Pretoria in 2007. He was awarded the second-best student poster price at the 12th International Conference on Harmful Algae in 2006 and the study was then published in the prestigious conference proceedings after a rigorous peer review process. This author became a Member (M) of International Society for the Study of Harmful Algae; International Mine Water Association; Water Institute of Southern Africa; Microscopy Society of Southern Africa and South African Council for Natural Scientific Professions. In 2008, he was appointed as a senior lecturer at University of Venda and in 2016 he was appointed as Associate 
18th JOHANNESBURG Int'I Conference on Science, Engineering, Technology \& Waste Management (SETWM-20) Nov. 16-17, 2020 Johannesburg (SA)

Professor. He is the first or second author of more than 86 research outputs ( 3 patents, 38 peer reviewed papers with more than thirds of these published in international journals with an impact factor; 41 peer reviewed conference proceedings and 3 technical reports and four book chapters). 